\title{
Hydrological Study Using SWAT and Global Weather, a Case Study in the Huai Khun Kaeo Watershed in Thailand
}

\author{
Sombat Chuenchooklin ${ }^{1, *}$, Udomporn Pangnakorn ${ }^{2}$ \\ ${ }^{1}$ Water Resources Research Center, Department of Civil Engineering, Faculty of Engineering, Naresuan University, Phitsanulok, Thailand \\ ${ }^{2}$ Department of Agricultural Science, Faculty of Agriculture Natural Resources and Environment, Naresuan University, Phitsanulok, Thailand
}

Email address:

sombatc $a$ nu.ac.th (S. Chuenchooklin), udompornp $a$ nu.ac.th (U. Pangnakorn)

${ }^{*}$ Corresponding author

\section{To cite this article:}

Sombat Chuenchooklin, Udomporn Pangnakorn. Hydrological Study Using SWAT and Global Weather, a Case Study in the Huai Khun Kaeo Watershed in Thailand. International Journal of Environmental Protection and Policy. Vol. 6, No. 2, 2018, pp. 36-41.

doi: $10.11648 /$ j.ijepp.20180602.13

Received: March 20, 2018; Accepted: May 22, 2018; Published: June 21, 2018

\begin{abstract}
The Huai Khun Kaeo watershed was chosen to study the hydrological productions from 2007 to 2013. There is lack of the hydrological observation data which can be considered as the Prediction in Ungauged Basin (PUB). It locates between the Sakae Krang river basin in Uthai Thani and the Tha Chin river basin in Chai Nat provinces, Thailand. The soil and water assessment tool (SWAT) was applied for the simulation of the hydrological response unit productions based on the Climate Forecast System Reanalysis (CFSR) from global weather data. The results of daily streamflow from the model were compared to the observed data at the hydrological observation station downstream end of the watershed. The results showed the Nash and Sutcliffe efficiency (NSE) of 0.10 , correlation $\left(\mathrm{R}^{2}\right)$ of 0.275 , and the root mean square error (RSME) of 23.8 with a mean discharge of 11.0 cubic meters per second, respectively.
\end{abstract}

Keywords: Hydrological Model, SWAT, CFSR, PUB

\section{Introduction}

The small to medium river basin is generally a lack of hydrological data collection from the field and difficulty in flood estimation which can be considered as Prediction in Ungauged Basin (PUB) [1]. Accurate estimates of stream runoff and other hydrologic quantities are needed for numerous purposes of water resources planning and management. The way of obtaining such estimates by modeling methods such as the Rational Method and the index-flood method have been widely used, which can be found such as the Hydrologic Modeling System (HMS) [2]. The worldwide physical based model such as the Soil and Water Assessment Tool (SWAT) [3], is a river basin scale model developed to quantify the impact of land management practices on water, sediment and agricultural chemical yields in large, complex watersheds with varying soils, land use and management conditions over long periods of time. SWAT main components include weather, surface runoff, return flow, percolation, evapotranspiration, transmission losses, pond and reservoir storage, crop growth and irrigation, groundwater flow, reach routing, nutrient and pesticide loading, and water transfer. In addition, other hydrodynamic also open source model of the River Analysis System (RAS), is designed to perform one and two-dimensional hydraulic calculations for a full network of natural and constructed channels with graphical user interface (GUI) [4]. It can be analytically for movable boundary sediment transport computations and water quality analysis too. The system contains several hydraulic design features that can be invoked once the basic water surface profiles are computed. Moreover, the distributed hydrological model such as the Integrated Flood Analysis System (IFAS) by PWRI [5] has been developed which can be applied to the very large watershed. However, IFAS has taken long simulation time than SWAT in comparing the result of the watershed.

Poor water management of existing diversion structures without any storage dam as a head-water source in the central plain of Thailand, including the Tha Chin and Sakae Krang river basins was reported. It is not realized in the estimation of the upstream discharges to those diversion structures with 
full potential $[6,7]$. Thus, this study aimed to analyze the daily streamflow discharge produced from the Huai Khun Kaeo upstream of the Huai Khot - Wang Man diversion point in the Nong Mamong, Chai Nat province and applied an open source geographic information system using QGIS interface for SWAT (QSWAT) [8]. The study was a part of the overall research topic, namely "Development of Supporting Mechanisms for Budget Planning of Water Resources and Agriculture based on the Application of Information Technological Linkages in the Chainat Province" which was sponsored by the Thailand Research Fund (TRF) in 2016 [9].

\section{Material and Method}

\subsection{Study Area}

The Huai Khun Kaeo watershed was chosen to study, whereas its locates between the southern part of the Sakae Krang river basin and the northern part of the Tha Chin river basin in Uthai Thani and Chai Nat provinces, Thailand. It originates from the ridge between Kanchanaburi and Uthai Thani provincial boundary. The Huai Khun Kaeo is a major stream and flows from the west to the eastern part of the basin and it flows to the Tha Chin River and Chaophraya River. The Huai Khot is a large tributary stream as sub-watershed joining the downstream junction of the Huai Khun Kaeo stream. The total drainage area of its watershed is $1,059 \mathrm{~km}^{2}$ measured at the hydrological observation station at C.51 from the Royal Irrigation Department (RID). The Huai Khot - Wang Man channel was planned to divert some part of flood as diversion flow from the Huai Khun Kaeo in Uthai Thani to Chai Nat provinces during the rainy season with the flow rate of $10-15 \mathrm{~m}^{3} / \mathrm{s}$. It connects to the retarding ponds along the canal systems in order to reduce flood peak with a storage capacity approx. of 3 million $\mathrm{m}^{3}$, which can be used for dry season crop approx. 960 ha [10]. In this study, the upper part of the basin at a diversion point and outlet with a drainage area of $880 \mathrm{~km}^{2}$ was chosen to study using the quantum geographic information system: QGIS as Figure 1.

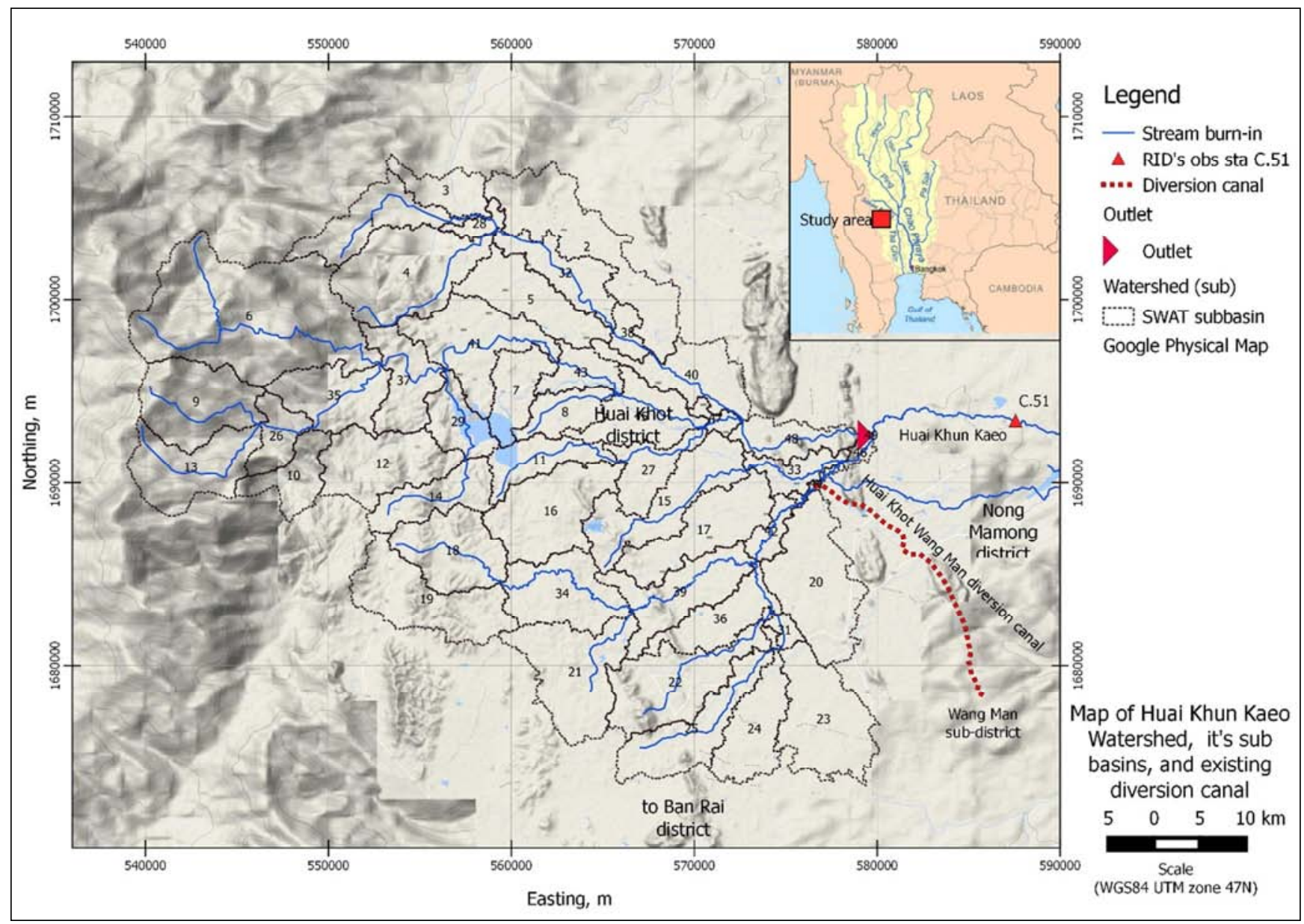

Figure 1. Location of Huai Khun Kaeo watershed, sub-basins, stream networks, outlet, RID's observation station (C.51), and existing diversion canal in QGIS's Google Maps using by physical plugin.

An existing diversion canal is a concrete lining channel with $15 \mathrm{~km}$ long, starting from a tributary stream of Huai Khun Kaeo in Ban Rai district, passing Wang Takian, Nong Mamong and ending Wang Man sub-districts in the Nong
Mamong district of the Chai Nat province, respectively. The purpose of constructing this canal was to convey a partial flood in Ban Rai to be stored in the provided retarding ponds. These storage water from the ponds will be used as irrigation 
water for a supplementary late wet season with agricultural land of 4,000 ha and supply in the dry season crop of 960 ha. A mean altitude of a proposed area is approx. $65 \mathrm{~m}$ above mean sea level: MSL. The problem in this area is uncertainty flood estimating to the head regulator of a diversion canal. An average annual rainfall of $1,028.5 \mathrm{~mm}$ and rainy day of
71.4 days reported by the RID's hydrological observation station. The annual runoff at C. 51 is approx. $280 \times 10^{6} \mathrm{~m}^{3}$.

The 49 sub-basins was divided with an average size of 16 $\mathrm{km}^{2}$ and layout of the stream networks upstream of an existing outlet in the basin and diversion canal using digital elevation models (DEM) of $30 \mathrm{~m}$ in resolution as Figure 2.

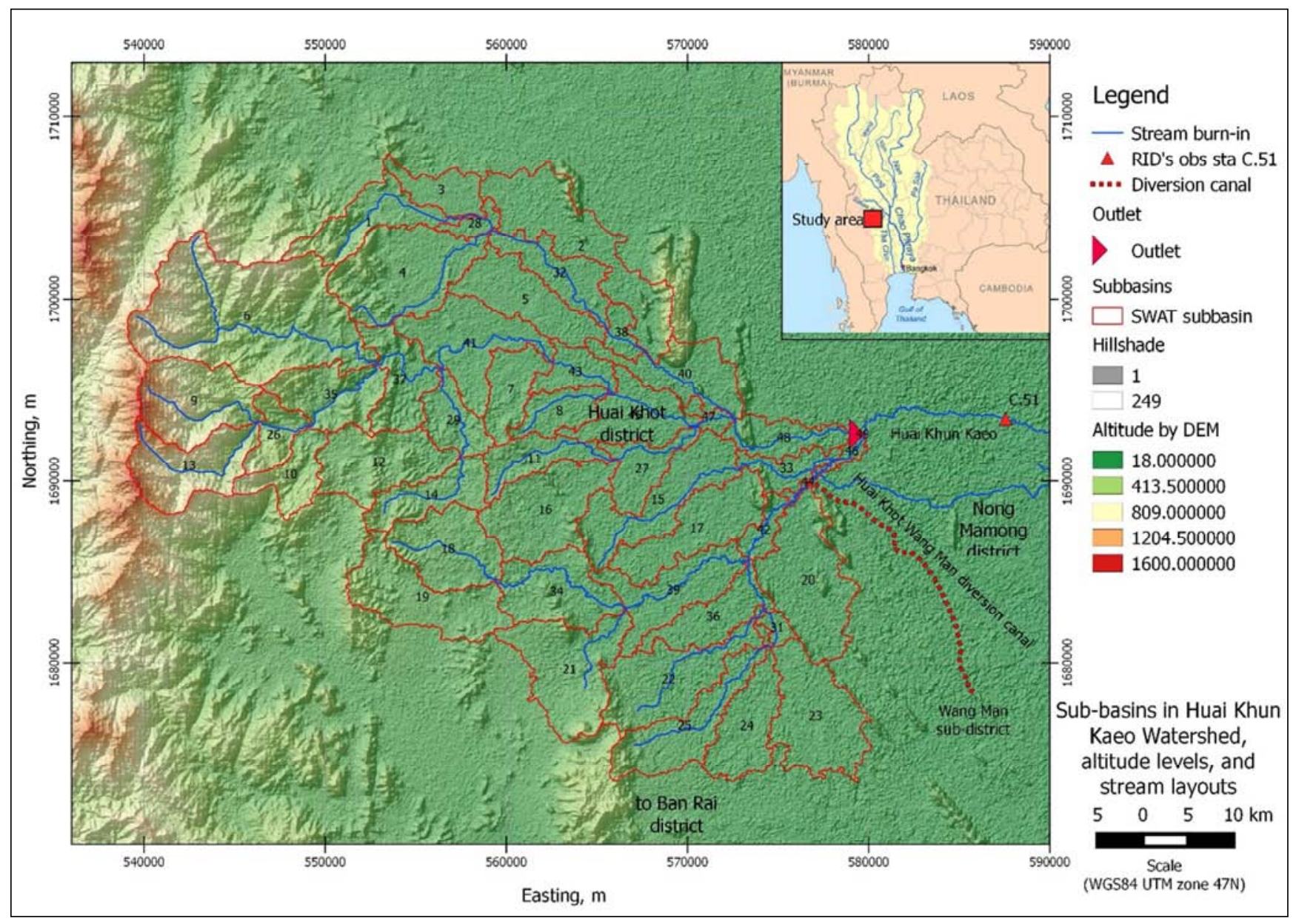

Figure 2. The basin terrain and stream layouts upstream of the outlet and diversion canal using DEM 30m.

\subsection{Hydrological Modelling}

The hydrological model applied SWAT through platform Quantum Geographic Information System: QGIS for the simulation of the hydrological response unit systems and head flow discharge to the outlet and a diversion point. The QGIS allows users to create many map layers using different projections and plugins with QSWAT [8]. Existing global land use map and soil map data as well as the Climate Forecast System Reanalysis (CFSR) as global weather data in this study obtained automatically using SWAT editor. Since CSFR data had proved that it could be reliably applied to watershed modelling across a variety of hydro-climate regimes and watersheds with a good stream flow predictions particular for PUB [11]. The model based on its topography, land use data, soil data, and the slope applied to divide smaller sub-basins with each hydrologic response units (HRU).

\subsection{Model Sensitivity}

The Nash and Sutcliffe efficiency (NSE) model [12], and the root mean square error (RSME) were used to test the model sensitivity while compared to the observed data particular with daily river flow discharge. NSE is computed as follows:

$$
\mathrm{NSE}=1-\left[\frac{\sum_{i=1}^{n}\left(Y_{i}^{o b s}-Y_{i}^{s i m}\right)^{2}}{\sum_{i=1}^{n}\left(Y_{i}^{o b s}-Y^{m e a n}\right)^{2}}\right]
$$

where $\mathrm{Y}_{\mathrm{i}}^{\text {obs }}$ is the $\mathrm{i}^{\text {th }}$ observation for the constituent being evaluated, Yisim is the $i^{\text {th }}$ simulated value of the constituent being evaluated, $\mathrm{Y}^{\text {mean }}$ is the mean of observed data for the constituent being evaluated, and $\mathrm{n}$ is the total number of observations. NSE ranges between $-\infty$ and 1.0 ( 1 inclusive), with NSE $=1$ being the optimal value. Values between 0.0 and 1.0 are generally viewed as acceptable levels of performance, whereas values $<0.0$ indicates that the mean 
observed value is a better predictor than the simulated values, which indicates unacceptable performance.

The root mean square error (RSME) is computed as follows:

$$
\mathrm{RSME}=\sqrt{\frac{\sum_{i=1}^{n}\left(Y_{i}^{o b s}-Y_{i}^{\text {sim }}\right)^{2}}{n}}
$$

RSME incorporates the benefits of error between simulated result and observed data.

Moreover, the production from SWAT with simulated daily runoff at particular reaches based on the correlation $\left(\mathrm{R}^{2}\right)$ of model results and observation data was used to test the model sensitivity too.

The observation daily runoff at the outlet and diversion points were interpolated by using the aerial weighing method based on observation data from RID's C.51.

\section{Results and Discussion}

The results of the QGIS combination of SWAT through its plugin when applied global DEM to be delineation the watershed showed the topographic upstream of the existing outlet and diversion point were divided into 49 sub-basins as shown in Figure 2 and full HRU showed in Figure 3, respectively. The simulation results of river discharge at the outlet in sub-basin no. 49 were modelled with 7 years recorded (2007-2013) as shown in Figure 4. The simulation results (Qsim) fitted to the observed data (Qobs) at the outlet point (C51) with Nash and Sutcliffe efficiency (NSE) of 0.1, correlation coefficient $\left(\mathrm{R}^{2}\right)$ of 0.2745 , root mean square error (RSME) of 23.8, and the mean streamflow discharge of 11.1 $\mathrm{m}^{3} / \mathrm{s}$, as shown in Figure 5 , respectively. The result of $\mathrm{R}^{2}$ was fair due to less number of the satellite rain-gauge grids from the CSFR, which has shown only two grids inside and others 2 grids outside the basin. Moreover, the global map data on land uses and soil types were quite older and larger scales than an existing topographical map. These leaded to low correlation. The mean daily flow out of all stream reaches and each sub-basin (unit in $\mathrm{m}^{3} / \mathrm{s}$ ) is shown in Figure 6.

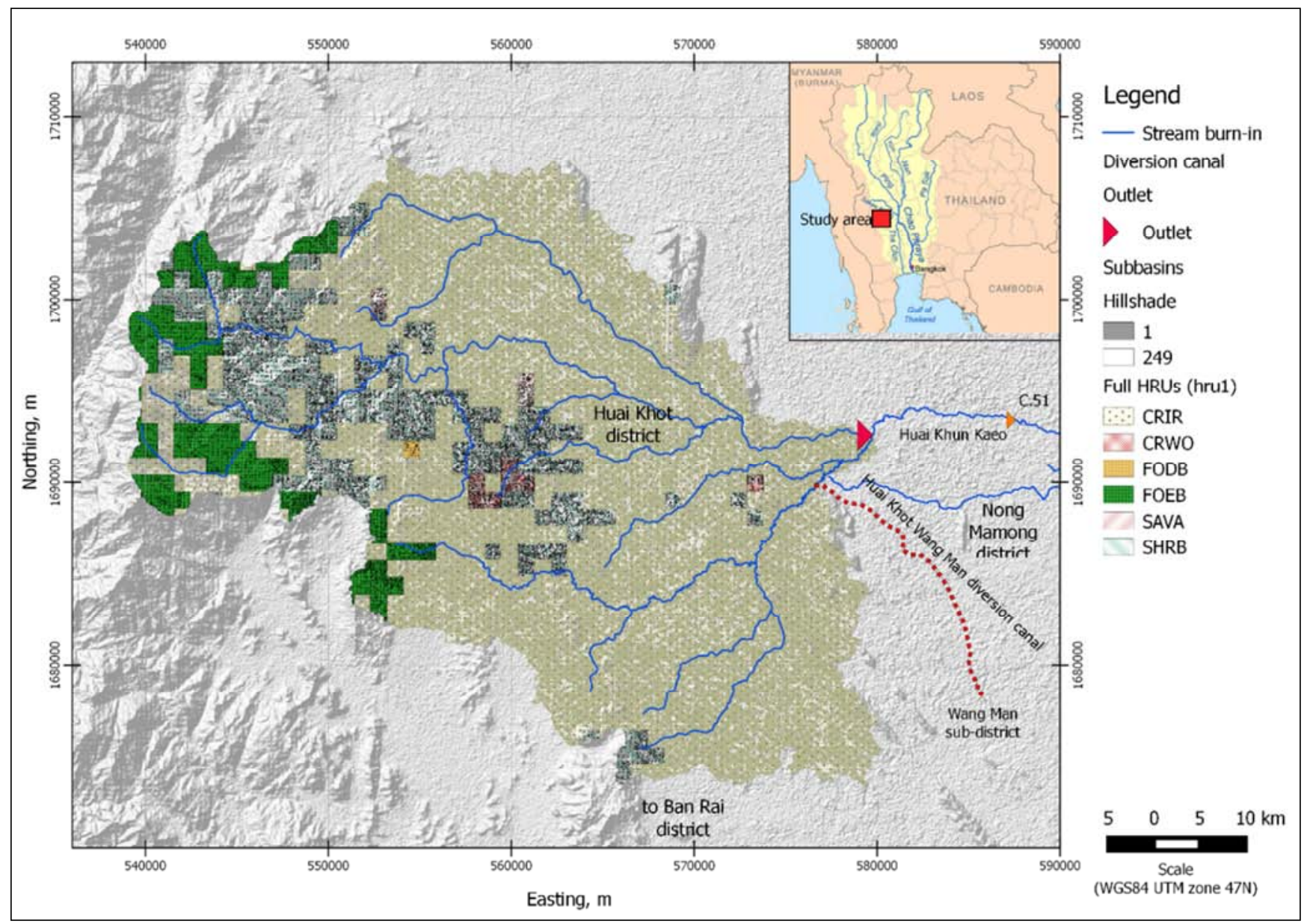

Figure 3. The full HRUs results of global land use types in study area using DEM 30m. 


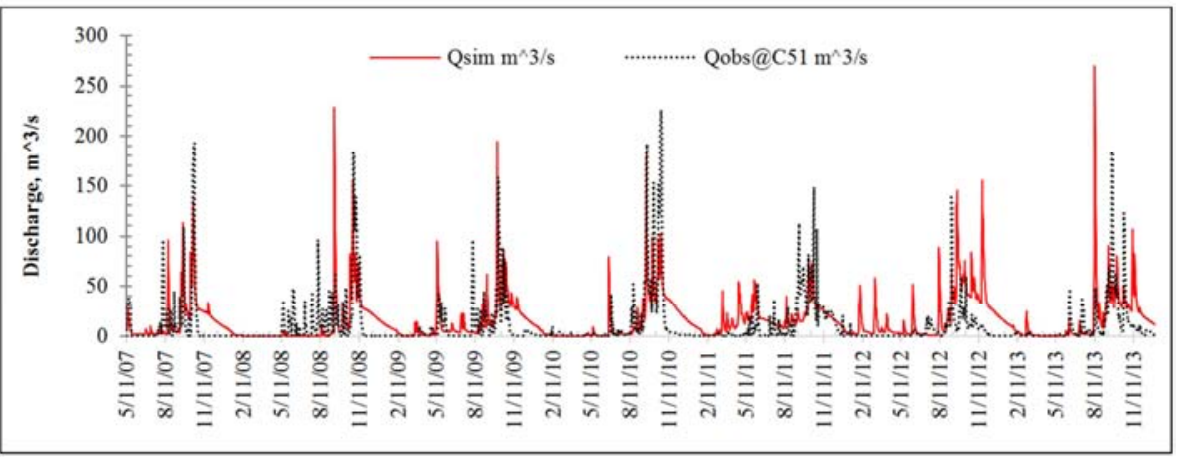

Figure 4. Comparing simulated and observed flow out of an outlet.

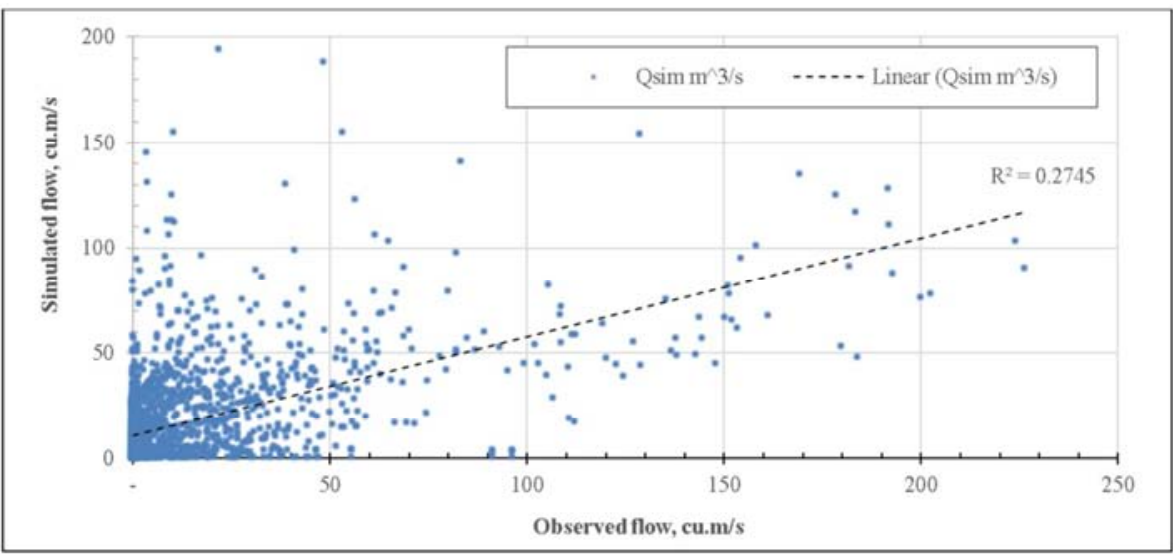

Figure 5. Correlation of simulated and observed flow out of the outlet.

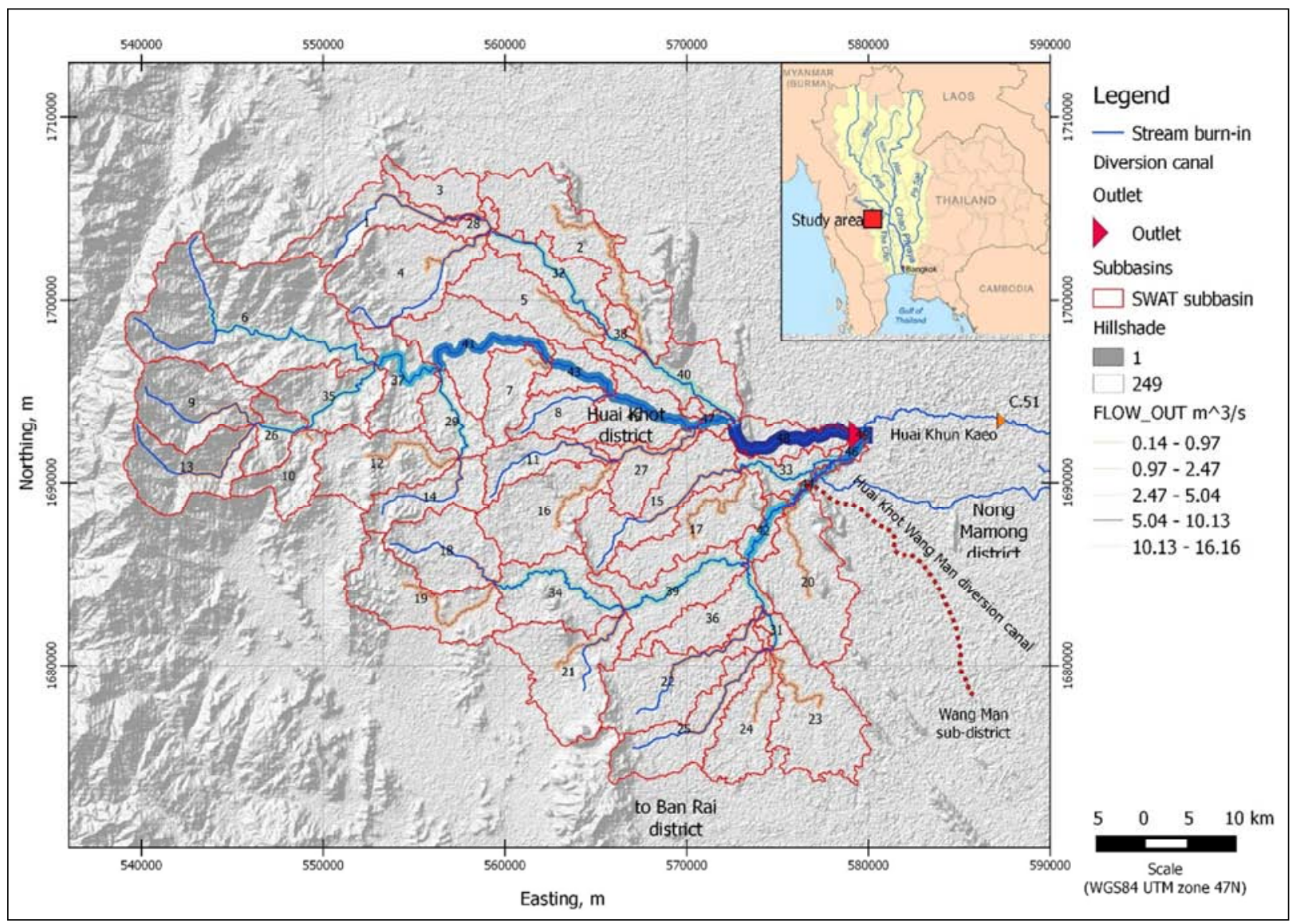

Figure 6. Mean daily flow out of all river reaches and sub-basin production at each outlet with average curve number (CN) of 81 (unit in $m^{3} / s$ ). 


\section{Conclusion}

The QSWAT can be applied to any either gauged or ungauged catchments with complex topography, many kinds of land uses, various soil types, and slope changes. It can be synthesized in the river flow hydrograph particular during large flood events upstream of the outlet or diversion points. Therefore, the manager could be efficiently managed the diversion water to their ponds and irrigation systems. The actual land uses, land coverages, and soil maps from field survey with the same scale as topographic map should be applied for further study. Moreover, the sub-watershed size should be smaller than the size from program recommendation such as $1 \mathrm{~km}^{2}$, the results should be better stream networks, HRUs, outflow hydrographs, and others with realistic results. However, smaller sub-watershed size will consume much computer capacity and take long simulation time than program recommendation size.

\section{Acknowledgements}

The authors would like to express our gratitude and thank the Thailand Research Fund (TRF) for funding research the subject "The Development of Supporting Mechanisms for Budget Planning of Water Resources and Agriculture based on the Application of Information Technological Linkages (ITLs) in Chainat Province" Contract Number RDG59A0015. We also thank the Director of the Chai Nat Irrigation Project, the Governor of the Chai Nat Province and the Strategy and Information for the Development of the Chai Nat Provincial Office, and the Mayor of the Nong Mamong Municipal in Chai Nat. Finally, we would like to thank the Dean of Faculty of Engineering and the President of Naresuan University (NU) to permit some faculty members to participate in this research.

\section{References}

[1] G. Blöschl, "Predictions in ungauged basins - where do we stand?", Proceedings of the International Association of Hydrological Sciences, Copernicus Publications, 373, 57-60, 2016, retrieved from http://www.proc-iahs.net/373/57/2016/.

[2] US Army Corps of Engineers (USACE), "Hydrological Modeling System HEC-HMS", 2017, retrieved from http://www.hec.usace.army.mil/.

[3] J. G. Arnold, and N. Fohrer, "SWAT2000: Current Capabilities and Research Opportunities", Applied Watershed Modeling. Hydrological Process, 19, 563-572, 2005, retrieved from http://dx.doi.org/10.1002/hyp.5611.

[4] US Army Corps of Engineers, "HEC-RAS's User Manual", 2016, retrieved from http://www.hec.usace.army.mil/.

[5] Public Works Research Institute (PWRI), "Integrated Flood Analysis Systems: IFAS Version 1.2 User's Manual”, 2017, retrieved from http://www.icharm.pwri.go.jp/research/ifas/.

[6] S. Hungspreug, W. Khao-uppatum, and S. Thanopanuwat, "Operational Flood Forecasting for Chao Phraya river Basin. Proceedings of the International Conference on The Chao Phraya Delta: Historical Development, Dynamics and Challenges of Thailand's Rice Bowl”, Kasetsart University, Bangkok, 12-15 December 2000.

[7] Japan International Cooperation Agency (JICA), "The Study on Integrated Plan for Flood Mitigation in Chao Phraya River Basin. Summary and Main Report", Royal Irrigation Department Kingdom of Thailand, 1999.

[8] Y. Dile, R. Srinivasan, and C. George, "QGIS Interface for SWAT (QSWAT version 1.5)”, 2018, https://swat.tamu.edu/.

[9] Thailand Research Fund (TRF), The Development of Supporting Mechanisms for Budget Planning of Water Resources and Agriculture based on the Application of Information Technological Linkages (ITLs) in Chainat Province, contract number RDG59A0015, proposed by the Water Resource Research Center of Naresuan University (in Thai and unpublished), 2016.

[10] Royal Irrigation Department (RID), "Reconnaissance Study of the Huai Khot Wang Man Diversion Canal Systems and Regulating Structures in Ban Rai and Nong Mamong Districts", Prepared by the Engineering Branch of Regional Irrigation Office 12 Chai Nat (in Thai and unpublished), 2015.

[11] D. R. Fuka, M. T. Walter, C. MacAlister, A. T. Degaetano, T. S. Steenhuis, Z. M. Easton, "Using the Climate Forecast System Reanalysis as weather input data for watershed models", Hydrological Processes, 2013, Published online in Wiley Online Library, DOI: 10.1002/hyp.10073.

[12] J. E. Nash, and J. V. Sutcliffe, "River flow forecasting through conceptual models: Part 1. A discussion of principles", Journal of Hydrology, 10 (3), p282-290, 1970. 